\title{
Interaction between Orexin Neurons and Monoaminergic Systems
}

\author{
Takeshi Sakurai ${ }^{a}$ b Yuki C. Saito ${ }^{a} \quad$ Masashi Yanagisawa $^{a}$ \\ a International Institute for Integrative Sleep Medicine (WPI-IIIS), University of Tsukuba, Tsukuba, Ibaraki, Japan; \\ ${ }^{b}$ Faculty of Medicine, University of Tsukuba, Tsukuba, Ibaraki, Japan
}

\begin{abstract}
Orexins have received a lot of attention as potent endogenous arousal-promoting peptides, and orexin receptor antagonists have shown clinical efficacy for the treatment of insomnia. Orexin neurons are thought to act primarily on monoaminergic neurons to maintain arousal and vigilance. In this chapter, we discuss the functional interaction between monoaminergic systems, including noradrenaline, serotonin and histamine, and orexin neurons, as well as interactions between the acetylcholine system and the orexin neurons, focusing, in particular, on their function in the regulation of sleep-wakefulness states. Orexin also has close interactions with the dopaminergic system, and many studies have suggested roles of orexin signaling in the reward system and roles for orexins in drug addiction.
\end{abstract}

(c) 2021 The Author(s)

Published by S. Karger AG, Basel

\section{Introduction}

Orexins are hypothalamic neuropeptides that play a highly important role in the maintenance of wakefulness. Orexin-A and orexin-B, which are derived from a common precursor peptide, bind to two subtypes of G-protein-coupled receptors, the orexin 1 receptor $\left(\mathrm{OX}_{1} \mathrm{R}\right)$ and the orexin 2 receptor $\left(\mathrm{OX}_{2} \mathrm{R}\right)$. Orexins potently increase wakefulness and suppress both non-rapid eye movement and rapid eye movement (REM) sleep [1].

In various mammalian species, including mice, rats, dogs and humans, loss of orexin neurons results in narcolepsy, a condition characterized by excessive daytime sleepiness, abnormally brief transitions to REM sleep from wakefulness (sleep-onset REM periods), and cataplexy, characterized by sudden loss of bilateral skeletal muscle tone [2-4]. This 
highlights a critical role of orexins in the maintenance of wakefulness. Animal models first suggested the involvement of orexin dysfunction in narcolepsy. Mice with a targeted deletion of the prepro-orexin gene (orexin ${ }^{-/-}$mice) and mice with genetic ablation of orexin neurons both showed a narcoleptic phenotype, characterized by abrupt behavioral arrests with muscle atonia (cataplexy), fragmented sleep-wakefulness states, and direct transitions from wakefulness to REM sleep $[5,6]$. In addition, functionally null mutations in the $\mathrm{OX}_{2} \mathrm{R}$ gene were found in familial narcoleptic dogs [7]. Consistently, $\mathrm{OX}_{2} \mathrm{R}^{-/-}$mice are also narcoleptic, although their phenotype is significantly milder than that of orexin $^{-/-}$mice or orexin/ataxin-3-transgenic mice [8]. In contrast, $O X_{1} R^{-/-}$mice do not show any overt abnormalities in sleep-wakefulness states $[1,9]$. These observations suggest that the $\mathrm{OX}_{2} \mathrm{R}$ mediated pathway has a pivotal role, although $\mathrm{OX}_{1} \mathrm{R}$ has an additional role in the maintenance of wakefulness. Orexin receptors are abundantly expressed in histaminergic, noradrenergic, and serotonergic neurons, as well as cholinergic neurons [10], which play critical roles for sleep-wakefulness regulation.

The discovery of a causal link between loss of orexin signaling and narcolepsy has brought about the possibility of novel therapies for the disorder. Indeed, we have demonstrated that acute intracerebroventricular administration of orexin-A maintained wakefulness, suppressed sleep, and inhibited cataplectic attacks in orexin/ataxin-3 transgenic mice [11]. In addition, a non-peptide $\mathrm{OX}_{2} \mathrm{R}$ agonist was shown to have potential value for treating narcolepsy $[12,13]$. Especially, TAK925 was reported to ameliorate symptoms of both type- 1 and type- 2 narcolepsy $[14,15]$. Orexin receptor agonists might also be beneficial for treating conditions of excessive daytime sleepiness. Likewise, dual orexin receptor antagonists, which antagonize both orexin receptors with similar affinity, have shown clinical efficacy for the treatment of insomnia $[16,17]$. Understanding the function of orexin receptors, in particular their roles in regulating monoaminergic neurons, is important for elucidating the mechanism by which the orexin system maintains wakefulness, as well as for understanding the effect of orexin receptor agonists/antagonists for treating hypersomnia and insomnia, respectively. Here, we discuss the functions of orexin and orexin receptors in the regulation of monoaminergic neurons, including noradrenergic, serotonergic, dopaminergic, and histaminergic neurons, as well as cholinergic neurons, all of which are localized in the brain stem nuclei. The role of these monoaminergic/cholinergic neurons in sleep-wakefulness regulation has been clarified by the correlation of their spontaneous firing frequency with the sleep-waking cycle [18-20]. Monoaminergic release in several cortical and subcortical sites was also correlated with the sleep-waking cycle [21-23].

\section{An Anatomical View of the Interactions between Orexin Neurons and Monoaminergic Systems}

Orexin neurons are distributed within the lateral hypothalamus and send projections throughout the brain and spinal cord. In particular, there are dense innervations to nuclei containing monoaminergic and cholinergic neurons in the brainstem and the hypothala- 


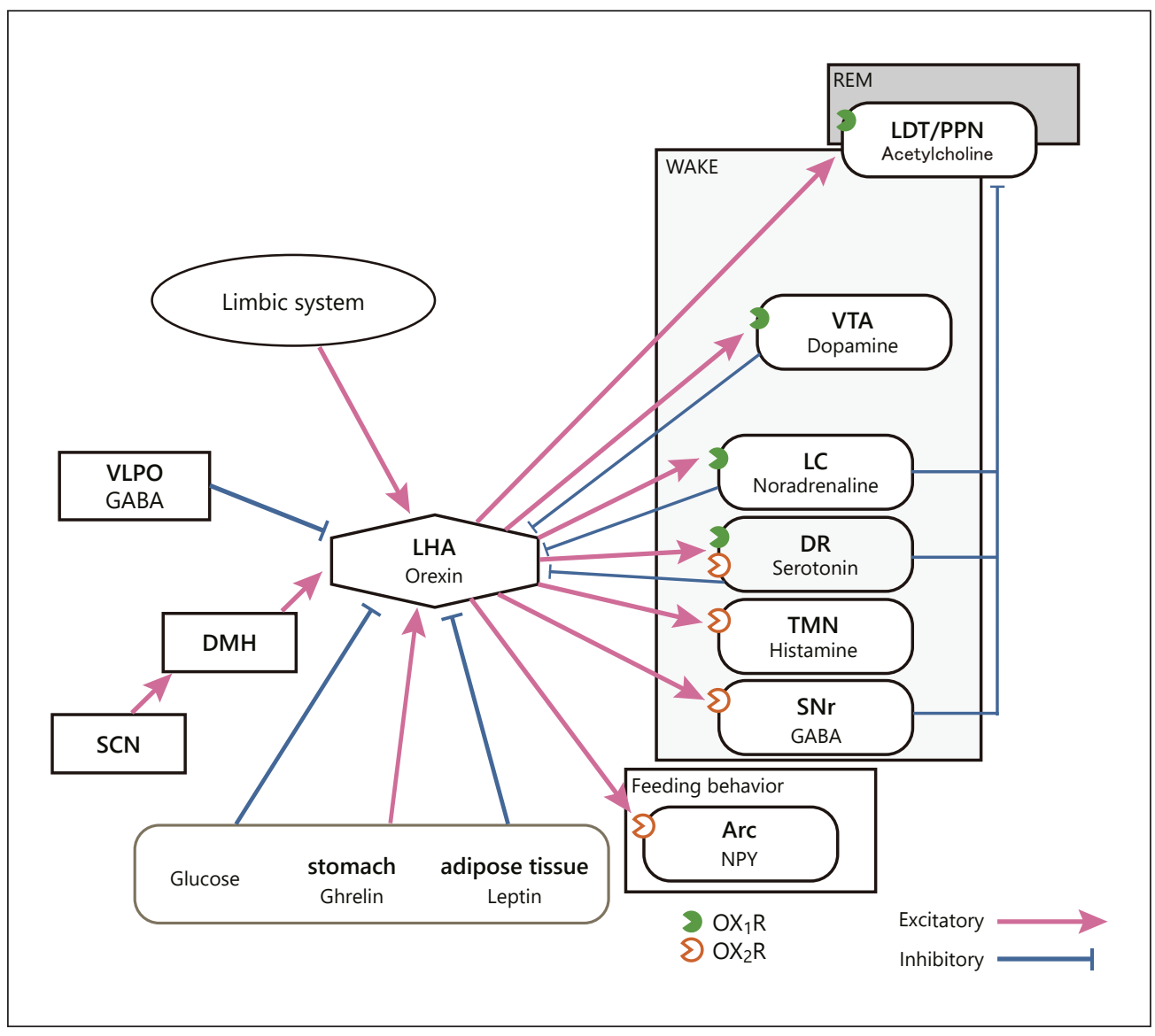

Fig. 1. Schematic drawing of input and output systems of orexin neurons. Orexin neurons receive abundant input from the regions implicated in stress and emotional processing. Neurons in the preoptic area, including those in the ventrolateral preoptic nucleus (VLPO) send especially rich innervations to orexin neurons. Orexin neurons send widespread projections throughout the brain, with especially dense projections to the noradrenergic, serotonergic, and histaminergic neurons in the posterior hypothalamus/brain stem regions. Arc, arcuate nucleus; $\mathrm{DMH}$, dorsomedial hypothalamus; DR, dorsal nucleus raphe; GABA, gamma-aminobutyric acid; LC, locus coeruleus; LDT, laterodorsal tegmental nucleus; LHA, lateral hypothalamic area; NPY, neuropeptide Y; PPN, pedunculopontine tegmental nucleus; REM, rapid eye movement; SCN, suprachiasmatic nuclei; SNr, substantia nigra reticulata; TMN, tuberomammillary nucleus; VTA, ventral tegmental area.

mus, including noradrenergic neurons of the locus coeruleus (LC), serotonergic neurons of the dorsal and median raphe nuclei (DR and MnR), histaminergic neurons of the tuberomammillary nucleus (TMN), and cholinergic neurons of the laterodorsal tegmental nucleus (LDT) and pedunculopontine tegmental nucleus (PPT) [1].

In situ hybridization studies have suggested that two subtypes of orexin receptors are differentially expressed in monoaminergic nuclei. Our previous work showed that within the LC, all vesicular monoamine transporter 2 (VMAT2)-positive noradrenergic neurons exhibited intense $O X_{1} R$ expression, whereas $O X_{2} R$ mRNA was exclusively detected 
in VMAT2-negative, non-noradrenergic neurons within the same nucleus [10]. In the TMN, on the contrary, all VMAT2-positive histaminergic neurons expressed $\mathrm{OX}_{2} R$ mRNA but not $O X_{1} R$. In the DR and MnR, both $O X_{1} R$ and $O X_{2} R$ mRNAs were expressed in approximately $90 \%$ of VMAT2-positive serotonergic neurons, suggesting that the majority of serotonergic neurons in these areas express both $O X_{1} R$ and $O X_{2} R$; whether or not these receptors are expressed in the same neurons has not as yet been clearly shown. Gad1-positive cells in the DR and MnR also expressed $O X_{1} R$ or $O X_{2} R$ mRNA, suggesting that GABAergic interneurons in the raphe nuclei express both orexin receptors. In the LDT and PPT, all vesicular acetylcholine transporter (VAChT)-positive cholinergic neurons expressed $O X_{1} R$ but not $O X_{2} R$ mRNA, suggesting that cholinergic neurons in these regions exclusively express $O X_{1} R$. Both $O X_{1} R$ and $O X_{2} R$ mRNA were also expressed in GABAergic and neurochemically unidentified neurons in the LDT and PPT. These anatomical observations using in situ hybridization histochemistry suggest close interaction between orexin neurons and monoaminergic/cholinergic systems, and that orexin neurons stabilize wakefulness by regulating these monoaminergic and cholinergic neurons (Fig. 1).

\section{Function of $\mathrm{OX}_{1} \mathrm{R}$ in the Locus Coeruleus}

Electrophysiological studies have shown that orexin-A and orexin-B increase the firing rates of monoaminergic neurons in the LC [24]. Orexin neurons send abundant projections to the LC. Orexin neurons that send projections to the LC receive input from a wide variety of brain regions, including the nucleus accumbens and the amygdala, suggesting the role of this connection in emotive function (Fig. 2). Application of orexin-A directly into the LC has been reported to suppress REM sleep and increase wakefulness [25]. $O X_{1} R^{-/-}$mice showed mild fragmentation of sleep-wakefulness states, which was significantly less than the wakefulness fragmentation observed in $\mathrm{OX}_{2} \mathrm{R}^{-/-}$mice. The highest fragmentation was observed in orexin ${ }^{-/-}$mice and $\mathrm{OX}_{1} \mathrm{R}^{-/-} ; \mathrm{OX}_{2} \mathrm{R}^{-/-}$mice $[1,26]$. This suggests that $\mathrm{OX}_{1} \mathrm{R}$ is indispensable for the maintenance of wakefulness in the absence of $\mathrm{OX}_{2} \mathrm{R}[10]$.

We observed that the maintenance of wakefulness in $\mathrm{OX}_{1} \mathrm{R}^{-/-} ; \mathrm{OX}_{2} \mathrm{R}^{-/-}$mice was significantly improved by noradrenergic neuron-selective restoration of $\mathrm{OX}_{1} \mathrm{R}$ in the $\mathrm{LC}$ to a level of wakefulness comparable to that in $\mathrm{OX}_{2} R^{-/-}$mice [27]. However, it was still significantly impaired as compared to that in wild-type mice, suggesting that LC noradrenergic neurons play a significant, but not the only, role for maintenance of wakefulness by orexin. Other regions are also required for the normal regulation of wakefulness. Consistently, a causal relationship between the firing of noradrenergic neurons in the LC and transitions from sleep to wakefulness has been shown by an optogenetic approach [28].

We found that a subpopulation of noradrenergic neurons in the LC projecting to the lateral amygdala (LA) receive synaptic input from orexin neurons [29]. Pharmacogenetic/ 

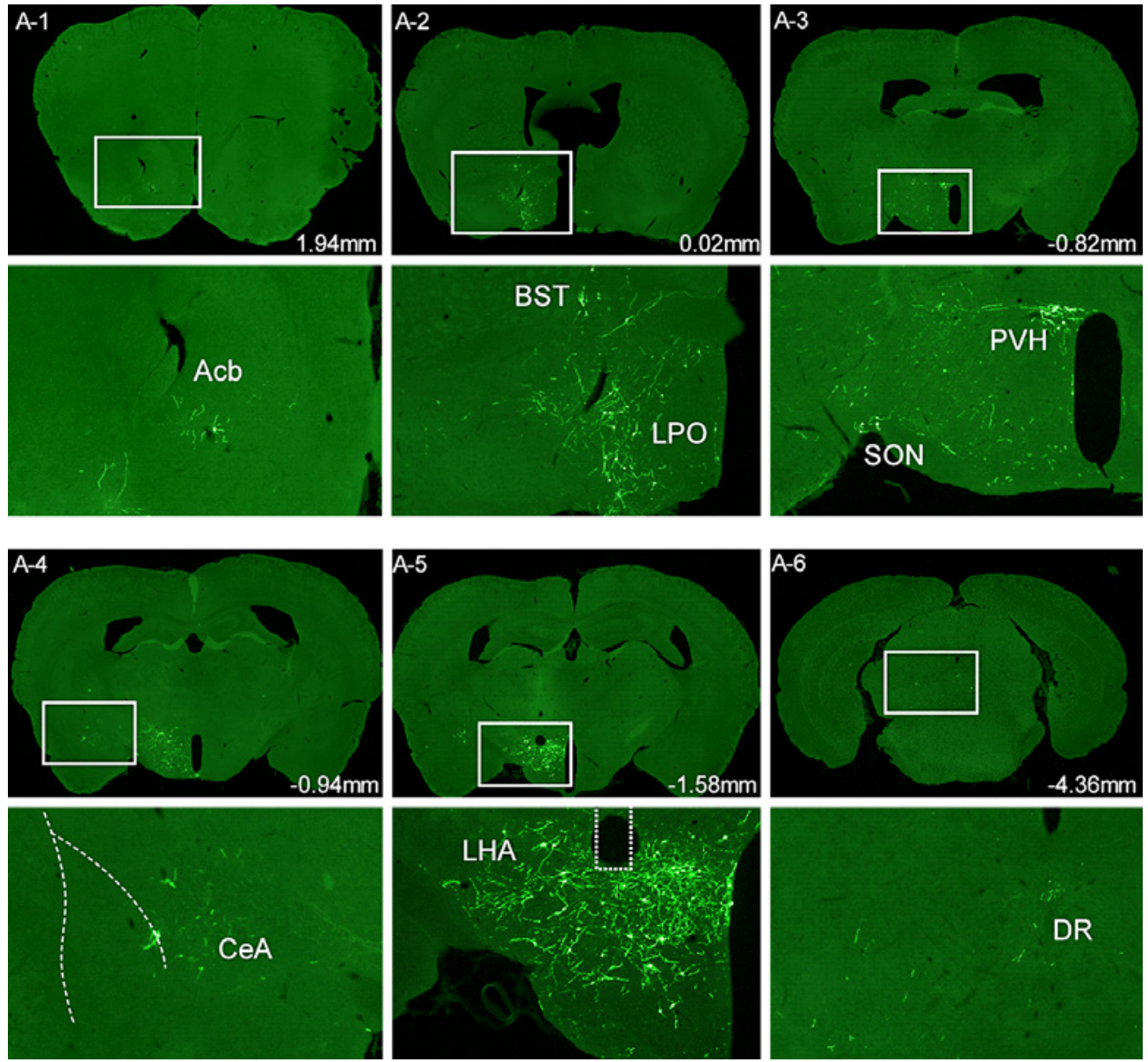

Fig. 2. Depiction of input of orexin neurons that send innervations to the locus coeruleus by the CTRIO approach [63]. We injected CAV2-DIO-FIp in the locus coeruleus, and then AAV2-DIO-TVA-mCherry and $A A V 2-D I O-R G$ in the LHA in orexin-Cre mice. After 14 days, SAD-dG-GFP(EnvA) was injected into the LHA to depict input to orexin neurons that send innervations to the LC. We observed similar distributions of input neurons with retrograde tracing of orexin neurons [45]. Acb, nucleus accumbens; BST, the bed nucleus of the stria terminalis; $\mathrm{CeA}$, central nucleus of the amygdala; CTRIO, cell type-specific tracing; $\mathrm{DR}$, dorsal raphe; LHA, lateral hypothalamic area; $\mathrm{LPO}$, lateral preoptic nucleus; $\mathrm{PVH}$, paraventricular hypothalamic nucleus; SON, supraoptic nucleus.

optogenetic silencing of this circuit, as well as acute blockade of $\mathrm{OX}_{1} \mathrm{R}$, decreased conditioned fear responses. In contrast, optogenetic stimulation of this circuit potentiated freezing behavior against a similar, but distinct, context or cue. An increase in orexinergic tone by fasting also potentiated the freezing behavior and LA activity, which were blocked by pharmacological blockade of $\mathrm{OX}_{1} \mathrm{R}$ in the LC. These observations suggest that the circuit involving orexin, LC and LA neurons mediates fear-related behavior, and that excitation of this pathway may cause fear generalization [29]. 


\section{Function of $O X_{1} R$ and $O X_{2} R$ in the Raphe Nuclei}

Orexin-A and orexin-B increase the firing rates of serotonergic neurons in the DR [30, 31]. In addition to the direct excitatory effects, orexins act indirectly to activate local inhibitory GABAergic input to serotonergic neurons [31]. This is consistent with expression of orexin receptors in GABAergic neurons of the DR/MnR [10].

Cataplexy frequently occurs in $\mathrm{OX}_{1} \mathrm{R}^{-/-} ; \mathrm{OX}_{2} \mathrm{R}^{-/-}$mice but rarely in $\mathrm{OX}_{2} \mathrm{R}^{-/-}$mice, and never in $O X_{1} R^{-/-}$mice $[8,9,26]$, suggesting that both $\mathrm{OX}_{1} \mathrm{R}$ and $\mathrm{OX}_{2} \mathrm{R}$-mediated pathways play roles in the inhibition of cataplexy. Consistently, DR serotonergic neurons, which express both $\mathrm{OX}_{1} \mathrm{R}$ and $\mathrm{OX}_{2} \mathrm{R}$, play a critical role in the prevention of cataplexy-like episodes [10].

The fact that DR serotonergic neurons show greatly reduced activity during cataplexy in narcoleptic dogs, and that selective serotonin reuptake inhibitors are effective for cataplexy, further support the important role of orexin signaling in DR serotonergic neurons in the inhibition of cataplexy [32]. Serotonergic neurons in the DR send dense projections to the PPT/LDT, substantia nigra pars compacta, and the amygdala - regions implicated in the regulation of REM sleep [1]. In particular, cataplexy is often triggered by strong emotions, and thus serotonergic modulation of the amygdala (a region important for emotion processing) may be relevant to the suppression of cataplexy. Consistently, the amygdala contains cataplexy-related neurons [33], as well as REM-active neurons that are inhibited by DR stimulation [34].

We found that restoration of $\mathrm{OX}_{2} \mathrm{R}$ expression in the $\mathrm{DR}$ of $\mathrm{OX}_{1} \mathrm{R}^{-/-} ; \mathrm{OX}_{2} \mathrm{R}^{-/-}$mice significantly decreased cataplexy-like attacks [35]. In addition, optogenetic excitation of serotonergic neurons in the DR or serotonergic fibers in the basolateral amygdala reduced cataplexy-like attacks, suggesting that orexin-mediated excitation of serotonergic neurons in the DR inhibits cataplexy-like attacks by acting on the basolateral amygdala [35]. Stimulating serotonin nerve terminals reduced amygdala activity. In addition, chemogenetic inhibition of the amygdala drastically decreased cataplexy-like episodes, whereas chemogenetic activation increased them [35]. These results suggest that DR serotonin neurons, as a downstream target of orexin neurons, inhibit cataplexy by reducing the activity of amygdala.

\section{Function of $\mathrm{OX}_{2} \mathrm{R}$ in the Tuberomammillary Nucleus}

Histaminergic neurons in the TMN are activated by orexins [36-38]. Mochizuki et al. [26] reported that focal restoration of $\mathrm{OX}_{2} \mathrm{R}$ in neurons of the posterior hypothalamus, including the TMN, ameliorated the fragmentation of wakefulness in $\mathrm{OX}_{2} \mathrm{R}$-null $\mathrm{OX}_{2} \mathrm{R}$ transcription-disrupted (TD) mice, in which a loxP-flanked transcription disrupter gene cassette prevents expression of functional $\mathrm{OX}_{2} \mathrm{R}$. However, no improvement of fragmentation of wakefulness in $\mathrm{OX}_{1} \mathrm{R}^{-/-} ; \mathrm{OX}_{2} \mathrm{R}^{-/-}$mice was observed when $\mathrm{OX}_{2} \mathrm{R}$ expression was restored in the TMN and adjacent parts of the posterior hypothalamus. This suggests that 
$\mathrm{OX}_{2} \mathrm{R}$ expression in the TMN may be sufficient to consolidate wakefulness only when $\mathrm{OX}_{1} \mathrm{R}$ is expressed in the brain. Alternatively, $\mathrm{OX}_{2} \mathrm{R}$ restoration in unidentified neurons in the posterior hypothalamus, other than the TMN, may play a role in the consolidation of wakefulness in $\mathrm{OX}_{2} \mathrm{R}$ TD mice. This is consistent with a finding that orexin-mediated sleep-to-wake transitions do not depend on the TMN histaminergic neurons [39].

\section{Interaction between Orexin and Cholinergic System}

Cholinergic neurons in the brain stem, which are located in the LDT/PPT, are well-known to play important roles in the regulation of sleep-wakefulness states. In addition, as mentioned earlier, orexin neurons send abundant projections to these regions, and LDT/PPT express orexin receptors. However, it has remained unclear how orexin affects the activity of cholinergic neurons in the LDT/PPT. These neurons express $\mathrm{OX}_{1} \mathrm{R}$, suggesting that orexin has excitatory effects on these cells, which is supported by an in vitro electrophysiology study [40]. Orexin neurons have also been shown to reciprocally interact with the basal forebrain cholinergic neurons [41, 42], which play an important role in attentive functions. Orexin neurons have been thought to partly promote arousal and attention through their projections to the basal forebrain cholinergic neurons [43].

\section{Feedback Regulation of Orexin Neurons by Monoaminergic Systems}

Our previous studies showed that noradrenaline (NA) and serotonin (5-HT) directly inhibit orexin neurons $[44,45]$, constituting negative feedback regulatory mechanisms for orexin neurons, although physiological relevance of these connections has not yet been revealed. However, NA and 5-HT also inhibit GABAergic neurons that send direct inhibitory projections to orexin neurons [45], suggesting that monoamines influence the activity of orexin neurons in a complex manner.

\section{Orexin and Dopaminergic System}

Orexin neurons send dense projections to the ventral tegmental area (VTA) with its dopaminergic neurons that themselves send rich innervations to the nucleus accumbens [46]. This suggests an interaction of the orexin with the reward system. The VTA expresses both subtypes of orexin receptors, with dopaminergic neurons predominantly expressing $\mathrm{OX}_{1} \mathrm{Rs}[47,48]$. Orexin signaling in the VTA has been implicated in reinforcement and reward-related processes via actions on VTA-dopamine neurons [49]. Orexin neurons may be activated by external reward-related stimuli and send information to the VTA to induce reinstatement of drug seeking via the $\mathrm{OX}_{1} \mathrm{R}$ [50]. Orexin neurons are excited during the behavioral expression of preferences for cues associated with reward [51], 
and administration of orexins, either intracerebroventricularly or locally into the VTA, can reinstate previously-extinguished drug-seeking or food-seeking behavior in rodents $[51,52]$.

There is much work to show that orexin neurons also play a part in addiction-related behaviors in rodents in response to different drugs of abuse [53-55]. Primarily, orexins are involved in the modulation of highly motivated reward-seeking, especially when this seeking is triggered by external cues. The $\mathrm{OX}_{1} \mathrm{R}$ appears to mainly mediate this function. For instance, orexin-A has been shown to promote motivation via $\mathrm{OX}_{1} \mathrm{R}$ signaling in a study in rats in which high levels of effort were required for seeking addictive drugs or highly palatable food in self-administration protocols [56].

In other experiments in rodents, the $\mathrm{OX}_{1} \mathrm{R}$ antagonist SB-334867 attenuated the expression of amphetamine-induced conditioned place preference [57] as well as the acquisition of locomotor sensitization to cocaine [58] and the expression of locomotor sensitization to amphetamine [59]. Together, these results suggest that orexins are essential for reward-seeking and primarily support motivated behavior which requires a high level of arousal [60].

\section{Conclusion}

Orexin neurons strongly excite monoaminergic neurons in the brainstem regions. Orexin neurons receive abundant input from a wide variety of brain regions, including the limbic system, paraventricular nucleus and preoptic areas [45]. Orexins also play an important role in the regulation of the reward system through modulation of the dopaminergic system in the VTA [61]. Orexin neurons have also been shown to be regulated by humoral factors, including leptin, glucose, and ghrelin [62]. These observations suggest the orexin neurons integrate animals' external and internal states to maintain vigilance levels accordingly, at least in part, through the regulation of monoaminergic neurons. Further understanding of input and output architecture of orexin neurons that send innervations to particular monoaminergic systems would provide us with further information about the mechanisms by which orexin neurons regulate monoaminergic neurons.

\section{Key Take-Home Points}

- Orexin neurons strongly excite monoaminergic neurons in the brain stem regions.

- These connections play important roles in the regulation of sleep and wakefulness.

\section{Conflict of Interest Statement}

T.S. and M.Y. received consultancy fees from Idorsia Pharmaceuticals Ltd during the development of this book. The authors have no further conflicts of interest to declare. 


\section{Funding Sources}

This work was supported by a JSPS KAKENHI Grant-in-Aid for Scientific Research (B) (JP 18H02595) and a KAKENHI Grant-in-Aid for Scientific Research on Innovative Areas, "Willdynamics" (16H06401).

\section{Author Contributions}

All authors were involved in the development and review of the chapter, approved the final version to be published and take responsibility for all aspects of the work.

\section{References}

1 Sakurai T: The neural circuit of orexin (hypocretin): maintaining sleep and wakefulness. Nat Rev Neurosci 2007;8:171-181.

2 Nishino S, Ripley B, Overeem S, Lammers GJ, Mignot E: Hypocretin (orexin) deficiency in human narcolepsy. Lancet 2000;355:39-40.

3 Peyron C, Faraco J, Rogers W, Ripley B, Overeem S, Charnay Y, et al: A mutation in a case of early onset narcolepsy and a generalized absence of hypocretin peptides in human narcoleptic brains. Nat Med 2000;6: 991-997.

4 Thannickal TC, Moore RY, Nienhuis R, Ramanathan L, Gulyani S, Aldrich M, et al: Reduced number of hypocretin neurons in human narcolepsy. Neuron 2000;27: 469-474.

5 Chemelli RM, Willie JT, Sinton CM, Elmquist JK, Scammell T, Lee C, et al: Narcolepsy in orexin knockout mice: molecular genetics of sleep regulation. Cell 1999;98: 437-451.

6 Hara J, Beuckmann CT, Nambu T, Willie JT, Chemelli RM, Sinton CM, et al: Genetic ablation of orexin neurons in mice results in narcolepsy, hypophagia, and obesity. Neuron 2001;30:345-354.

7 Lin L, Faraco J, Li R, Kadotani H, Rogers W, Lin X, et al. The sleep disorder canine narcolepsy is caused by a mutation in the hypocretin/orexin receptor 2 gene. Cell 1999;98:365-376.

8 Willie JT, Chemelli RM, Sinton CM, Tokita S, Williams SC, Kisanuki YY, et al: Distinct narcolepsy syndromes in orexin receptor-2 and orexin null mice: molecular genetic dissection of non-REM and REM sleep regulatory processes. Neuron 2003;38:715-730.

9 Hondo M, Nagai K, Ohno K, Kisanuki Y, Willie JT, Watanabe T, et al: Histamine-1 receptor is not required as a downstream effector of orexin-2 receptor in maintenance of basal sleep/wake states. Acta Physiol (Oxf) 2010;198:287-294.

10 Mieda M, Hasegawa E, Kisanuki Y, Sinton C, Yanagisawa M, Sakurai T: Differential roles of orexin receptor- 1 and- 2 in the regulation of non-REM and REM sleep. J Neurosci 2011;31:6518-6526.
11 Mieda M, Willie JT, Hara J, Sinton CM, Sakurai T, Yanagisawa M: Orexin peptides prevent cataplexy and improve wakefulness in an orexin neuron-ablated model of narcolepsy in mice. Proc Natl Acad Sci USA 2004; 101:4649-4654.

12 Irukayama-Tomobe Y, Ogawa Y, Tominaga H, Ishikawa Y, Hosokawa N, Ambai S, et al: Nonpeptide orexin type2 receptor agonist ameliorates narcolepsy-cataplexy symptoms in mouse models. Proc Natl Acad Sci USA 2017;114:5731-5736.

13 Nagahara T, Saitoh T, Kutsumura N, Irukayama-Tomobe Y, Ogawa Y, Kuroda D, et al: Design and synthesis of non-peptide, selective orexin receptor 2 agonists. J Med Chem 2015;58:7931-7937.

14 Tanaka S, Evans R, Alexander R, Imazaki M, Touno S, Shimizu K, et al: PO6. Selective orexin 2 receptor agonist TAK-925 to treat narcolepsy: results of a randomized, double-blind, placebo-controlled, multiple-ascending-dose, phase 1 study in patients with narcolepsy type 1. J Sleep Res 2020;29:e13181.

15 Tanaka S, Evans R, Alexander R, Imazaki M, Touno S, Shimizu K, et al: P206. Selective orexin 2 receptor agonist TAK-925 to treat narcolepsy: results of a randomized, double-blind, placebo-controlled, multiple-ascending-dose, phase 1 study in patients with narcolepsy type 2. J Sleep Res 2020;29:e13181.

16 Winrow CJ, Renger JJ: Discovery and development of orexin receptor antagonists as therapeutics for insomnia. Br J Pharmacol 2014;171:283-293.

17 Beuckmann CT, Suzuki M, Ueno T, Nagaoka K, Arai T, Higashiyama $\mathrm{H}$ : In vitro and in silico characterization of lemborexant (E2006), a novel dual orexin receptor antagonist. J Pharmacol Exp Ther 2017;362:287-295.

18 Puizillout JJ, Gaudin-Chazal G, Daszuta A, Seyfritz N, Ternaux JP: Release of endogenous serotonin from "encéphale isolé" cats. II - Correlations with raphe neuronal activity and sleep and wakefulness. J Physiol (Paris) $1979 ; 75: 531-537$.

19 Trulson ME, Jacobs BL: Raphe unit activity in freely moving cats: correlation with level of behavioral arousal. Brain Res 1979;163:135-150. 
20 McCormick DA, Pape HC, Williamson A: Actions of norepinephrine in the cerebral cortex and thalamus: implications for function of the central noradrenergic system. Prog Brain Res 1991;88:293-305.

21 Portas CM, Bjorvatn B, Fagerland S, Grønli J, Mundal V, Sørensen E, et al: On-line detection of extracellular levels of serotonin in dorsal raphe nucleus and frontal cortex over the sleep/wake cycle in the freely moving rat. Neuroscience 1998;83:807-814.

22 Léna I, Parrot S, Deschaux O, Muffat-Joly S, Sauvinet V, Renaud B, et al: Variations in extracellular levels of dopamine, noradrenaline, glutamate, and aspartate across the sleep-wake cycle in the medial prefrontal cortex and nucleus accumbens of freely moving rats. J Neurosci Res 2005;81:891-899.

23 Chu M, Huang ZL, Qu WM, Eguchi N, Yao MH, Urade Y: Extracellular histamine level in the frontal cortex is positively correlated with the amount of wakefulness in rats. Neurosci Res 2004;49:417-420.

24 Horvath TL, Peyron C, Diano S, Ivanov A, Aston-Jones G, Kilduff TS, et al: Hypocretin (orexin) activation and synaptic innervation of the locus coeruleus noradrenergic system. J Comp Neurol 1999;415:145-159.

25 Bourgin P, Huitrón-Résendiz S, Spier AD, Fabre V, Morte B, Criado JR, et al: Hypocretin-1 modulates rapid eye movement sleep through activation of locus coeruleus neurons. J Neurosci 2000;20:7760-7765.

26 Mochizuki T, Arrigoni E, Marcus JN, Clark EL, Yamamoto M, Honer M, et al: Orexin receptor 2 expression in the posterior hypothalamus rescues sleepiness in narcoleptic mice. Proc Natl Acad Sci USA 2011;108:44714476.

27 Hasegawa E, Yanagisawa M, Sakurai T, Mieda M: Orexin neurons suppress narcolepsy via 2 distinct efferent pathways. J Clin Invest 2014;124:604-616.

28 Carter ME, Yizhar O, Chikahisa S, Nguyen H, Adamantidis A, Nishino S, et al: Tuning arousal with optogenetic modulation of locus coeruleus neurons. Nat Neurosci 2010;13:1526-1533.

29 Soya S, Takahashi TM, McHugh TJ, Maejima T, Herlitze $\mathrm{S}$, Abe M, et al: Orexin modulates behavioral fear expression through the locus coeruleus. Nat Commun 2017;8:1606.

30 Brown RE, Sergeeva O, Eriksson KS, Haas HL: Orexin A excites serotonergic neurons in the dorsal raphe nucleus of the rat. Neuropharmacology 2001;40:457-459.

31 Liu RJ, van den Pol AN, Aghajanian GK: Hypocretins (orexins) regulate serotonin neurons in the dorsal raphe nucleus by excitatory direct and inhibitory indirect actions. J Neurosci 2002;22:9453-9464.

32 Hirai N, Nishino S: Recent advances in the treatment of narcolepsy. Curr Treat Options Neurol 2011;13:437457.

33 Gulyani S, Wu MF, Nienhuis R, John J, Siegel JM: Cataplexy-related neurons in the amygdala of the narcoleptic dog. Neuroscience 2002;112:355-365.

34 Jha SK, Ross RJ, Morrison AR: Sleep-related neurons in the central nucleus of the amygdala of rats and their modulation by the dorsal raphe nucleus. Physiol Behav 2005;86:415-426.
35 Hasegawa E, Maejima T, Yoshida T, Masseck OA, Herlitze S, Yoshioka M, et al: Serotonin neurons in the dorsal raphe mediate the anticataplectic action of orexin neurons by reducing amygdala activity. Proc Natl Acad Sci USA 2017;114:E3526-e35.

36 Bayer L, Eggermann E, Serafin M, Saint-Mleux B, Mach ard D, Jones B, et al: Orexins (hypocretins) directly excite tuberomammillary neurons. Eur J Neurosci 2001; 14:1571-1575.

37 Eriksson KS, Sergeeva O, Brown RE, Haas HL: Orexin/ hypocretin excites the histaminergic neurons of the tuberomammillary nucleus. J Neurosci 2001;21:92739279.

38 Yamanaka A, Tsujino N, Funahashi H, Honda K, Guan JL, Wang QP, et al: Orexins activate histaminergic neurons via the orexin 2 receptor. Biochem Biophys Res Commun 2002;290:1237-1245.

39 Carter ME, Adamantidis A, Ohtsu H, Deisseroth K, de Lecea L: Sleep homeostasis modulates hypocretin-mediated sleep-to-wake transitions. J Neurosci 2009;29: 10939-10949.

40 Kohlmeier KA, Tyler CJ, Kalogiannis M, Ishibashi M, Kristensen MP, Gumenchuk I, et al: Differential actions of orexin receptors in brainstem cholinergic and monoaminergic neurons revealed by receptor knockouts: implications for orexinergic signaling in arousal and narcolepsy. Front Neurosci 2013;7:246.

41 Eggermann E, Serafin M, Bayer L, Machard D, SaintMleux B, Jones BE, et al: Orexins/hypocretins excite basal forebrain cholinergic neurones. Neuroscience 2001; 108:177-181.

42 Sakurai T, Nagata R, Yamanaka A, Kawamura H, Tsujino N, Muraki Y, et al: Input of orexin/hypocretin neurons revealed by a genetically encoded tracer in mice. Neuron 2005;46:297-308.

43 Villano I, Messina A, Valenzano A, Moscatelli F, Esposito $\mathrm{T}$, Monda $\mathrm{V}$, et al: Basal forebrain cholinergic system and orexin neurons: effects on attention. Front Behav Neurosci 2017;11:10.

44 Muraki Y, Yamanaka A, Tsujino N, Kilduff TS, Goto K, Sakurai T: Serotonergic regulation of the orexin/hypocretin neurons through the 5-HT1A receptor. J Neurosci 2004;24:7159-7166.

45 Saito YC, Maejima T, Nishitani M, Hasegawa E, Yanagawa Y, Mieda M, et al: Monoamines inhibit GABAergic neurons in ventrolateral preoptic area that make direct synaptic connections to hypothalamic arousal neurons. J Neurosci 2018;38:6366-6378.

46 Yoshida K, McCormack S, España RA, Crocker A, Scammell TE: Afferents to the orexin neurons of the rat brain. J Comp Neurol 2006;494:845-861.

47 Marcus JN, Aschkenasi CJ, Lee CE, Chemelli RM, Saper $\mathrm{CB}$, Yanagisawa M, et al: Differential expression of orexin receptors 1 and 2 in the rat brain. J Comp Neurol 2001;435:6-25.

48 Mieda M, Tsujino N, Sakurai T: Differential roles of orexin receptors in the regulation of sleep/wakefulness. Front Endocrinol (Lausanne) 2013;4:57. 
49 Balcita-Pedicino JJ, Sesack SR: Orexin axons in the rat ventral tegmental area synapse infrequently onto dopamine and gamma-aminobutyric acid neurons. J Comp Neurol 2007;503:668-684.

50 James MH, Charnley JL, Levi EM, Jones E, Yeoh JW, Smith DW, et al: Orexin-1 receptor signalling within the ventral tegmental area, but not the paraventricular thalamus, is critical to regulating cue-induced reinstatement of cocaine-seeking. Int J Neuropsychopharmacol 2011; 14:684-690.

51 Harris GC, Wimmer M, Aston-Jones G: A role for lateral hypothalamic orexin neurons in reward seeking. Nature 2005;437:556-559.

52 Boutrel B, Kenny PJ, Specio SE, Martin-Fardon R, Markou A, Koob GF, et al: Role for hypocretin in mediating stress-induced reinstatement of cocaine-seeking behavior. Proc Natl Acad Sci USA 2005;102:19168-19173.

53 España RA, Melchior JR, Roberts DC, Jones SR: Hypocretin 1/orexin $A$ in the ventral tegmental area enhances dopamine responses to cocaine and promotes cocaine self-administration. Psychopharmacology (Berl) 2011; 214:415-426.

54 Mahler SV, Smith RJ, Moorman DE, Sartor GC, AstonJones G: Multiple roles for orexin/hypocretin in addiction. Prog Brain Res 2012;198:79-121.

55 Martin-Fardon R, Boutrel B: Orexin/hypocretin (Orx/ $\mathrm{Hcrt}$ ) transmission and drug-seeking behavior: is the paraventricular nucleus of the thalamus (PVT) part of the drug seeking circuitry? Front Behav Neurosci 2012; 6:75.
56 Borgland SL, Chang SJ, Bowers MS, Thompson JL, Vittoz N, Floresco SB, et al: Orexin A/hypocretin-1 selectively promotes motivation for positive reinforcers. J Neurosci 2009;29:11215-11225.

57 Hutcheson DM, Quarta D, Halbout B, Rigal A, Valerio E, Heidbreder C: Orexin-1 receptor antagonist SB-334867 reduces the acquisition and expression of cocaine-conditioned reinforcement and the expression of amphetamine-conditioned reward. Behav Pharmacol 2011;22: 173-181.

58 Borgland SL, Taha SA, Sarti F, Fields HL, Bonci A: Orexin A in the VTA is critical for the induction of synaptic plasticity and behavioral sensitization to cocaine. Neuron 2006;49:589-601.

59 Quarta D, Valerio E, Hutcheson DM, Hedou G, Heidbreder C: The orexin-1 receptor antagonist SB-334867 reduces amphetamine-evoked dopamine outflow in the shell of the nucleus accumbens and decreases the expression of amphetamine sensitization. Neurochem Int 2010;56:11-15.

60 James MH, Mahler SV, Moorman DE, Aston-Jones G: A decade of orexin/hypocretin and addiction: where are we now? Curr Top Behav Neurosci 2017;33:247-281.

61 Sakurai T: The role of orexin in motivated behaviours. Nat Rev Neurosci 2014;15:719-731.

62 Yamanaka A, Beuckmann CT, Willie JT, Hara J, Tsujino $\mathrm{N}$, Mieda M, et al: Hypothalamic orexin neurons regulate arousal according to energy balance in mice. Neuron 2003;38:701-713.

63 Schwarz, LA et al. Viral-genetic tracing of the inputoutput organization of a central noradrenaline circuit. Nature 2015;524:88-92.

Takeshi Sakurai

International Institute for Integrative Sleep Medicine (WPI-IIIS), University of Tsukuba

1-1-1 Tennodai

Tsukuba, Ibaraki 305-8575 (Japan)

sakurai.takeshi.gf@u.tsukuba.ac.jp 